\title{
Fast and safe fabrication of a free-standing chitosan/alginate nanomembrane to promote stem cell delivery and wound healing
}

This article was published in the following Dove Press journal:

International Journal of Nanomedicine

3 June 2016

Number of times this article has been viewed

\author{
Yi Kongl,2,* \\ Rui Xu ${ }^{1, *}$ \\ Mohammad Ali Darabi \\ Wen Zhong ${ }^{3}$ \\ Gaoxing Luo' \\ Malcolm MQ Xing ${ }^{1,2}$ \\ Jun $\mathrm{Wu}^{\prime}$ \\ 'Institute of Burn Research, \\ Southwest Hospital, State Key \\ Laboratory of Trauma, Burns, and \\ Combined Injury, Chongqing Key \\ Laboratory for Diseases Proteomics, \\ Third Military Medical University, \\ Chongqing, People's Republic of \\ China; ${ }^{2}$ Department of Mechanical \\ Engineering, Biochemistry and \\ Medical Genetics, Children's \\ Hospital Research Institute of \\ Manitoba, ${ }^{3}$ Department of Biosystem \\ Engineering, University of Manitoba, \\ Winnipeg, MB, Canada \\ *These authors contributed equally \\ to this work
}

Correspondence: Jun Wu Institute of Burn Research, Southwest Hospital, State Key Laboratory of Trauma, Burns, and Combined Injury, Third Military Medical University, 30 Gaotanyan Street, Chongqing 400038, People's Republic of China

Tel +862368752688

Email editorinchief@burninchina.com

Malcolm MQ Xing

Department of Mechanical Engineering, Biochemistry and Medical Genetics, Children's Hospital Research Institute of Manitoba, University of Manitoba, Winnipeg, MB R3T 2N2, Canada $\mathrm{Tel}+$ | 204480 |396

Email malcolm.xing@umanitoba.ca

\begin{abstract}
Polymeric ultrathin membranes that are compatible with cells offer tremendous advantages for tissue engineering. In this article, we report a free-standing nanomembrane that was developed using a layer-by-layer self-assembly technique with a safe and sacrificial substrate method. After ionization, two oppositely charged polyelectrolytes, alginate and chitosan, were alternately deposited on a substrate of a solidified gelatin block to form an ultrathin nanomembrane. The space between the two adjacent layers was $\sim 200 \mathrm{~nm}$. The thickness of the nanomembrane was proportional to the number of layers. The temperature-sensitive gelatin gel served as a sacrificial template at $37^{\circ} \mathrm{C}$. The free-standing nanomembrane promoted bone marrow stem cell adhesion and proliferation. Fluorescence-activated cell sorting was used to analyze green-fluorescent-protein-positive mesenchymal stem cells from the wounds, which showed a significantly high survival and proliferation from the nanomembrane when cells were transplanted to mouse dorsal skin that had a full-thickness burn. The bone-marrow-stem-cellloaded nanomembrane also accelerated wound contraction and epidermalization. Therefore, this methodology provides a fast and facile approach to construct free-standing ultrathin scaffolds for tissue engineering. The biocompatibility and free-standing nature of the fabricated nanomembrane may be particularly useful for stem cell delivery and wound healing.
\end{abstract}

Keywords: nanomembrane, layer-by-layer, cell delivery, wound healing

\section{Introduction}

Layer-by-layer (LBL) self-assembly is a thin film fabrication technique. ${ }^{1}$ Initially recommended by Decher et al in $1992,{ }^{2}$ this technique fabricates thin films by alternately depositing layers of oppositely charged polyelectrolytes ${ }^{3}$ by noncovalent linkages, such as hydrogen bonding, electrostatic interactions, and hydrophobic interactions. ${ }^{4,5}$ In terms of its versatility, the application of LBL-deposited films has been explored for biological, biochemical, and biomedical fields, such as in biosensors, ${ }^{6}$ biomotors, ${ }^{7}$ bioreactors, ${ }^{8}$ drug delivery, ${ }^{9}$ and tissue engineering. ${ }^{10}$

Several different processes have been selected to produce substrates for freestanding nanomembranes. However, the processes for forming nanomembranes are usually potentially unsafe, time-consuming, and wasteful of materials. For instance, in the study by Caridade et al, silicon wafers, polystyrene, polypropylene, and Teflon were chosen as the substrate for the deposition of polyelectrolytes. ${ }^{11}$ However, the membrane was only detachable on the polystyrene and polypropylene substrate via handling with tweezers when the multilayer film was dried, and it was unsafe to acquire the nanomembrane. In the study by Fujie et al, they designed an acetone-soluble photoresist as the substrate for the LBL process. The polysaccharide nanosheet was 
detached from the sacrificial layer when it was dissolved in acetone. $^{3}$ The process is time-consuming, and the organic solvent is not tissue friendly. Our previous works developed a method for stem cell adhesion on a chitosan (CHI)-alginate (ALG), alternately deposited nanofilm. Briefly, the cells were initially seeded on a poly( $N$-isopropylacrylamide)-grafted temperature-sensitive surface on a glass wafer, followed by the LBL deposition of CHI and ALG in an orderly manner on the surface of the cell sheet. ${ }^{12}$ Nevertheless, this method was time-consuming, and complex steps were required to finish the polyelectrolyte coating on the cell sheet. A perfect environment for cells is unlikely to be created for such a time-consuming LBL procedure. Thus, the bioactivity of the cells would probably be decreased. Hence, the disadvantages extensively limited the prospects for further study and the application of this nanomembrane for clinical targets.

To meet all the abovementioned requirements, a fast, safe, and cell-compatible pre-free-standing technique is crucial. Thus, because it is an ordinary but special candidate, solidified gelatin was selected as the sacrificial substrate to liberate the nanomembrane. Gelatin is a denatured collagen that exhibits wide-ranging applications in tissue engineering. It is well characterized as a cell-compatible and cell-adhesive primary unit, and it works as a drug carrier and as a cell deliverer. ${ }^{13,14}$ Interestingly, gelatin forms a viscous solution when dissolved in hot water and will experience a sol-gel phase transition when it decreases to room temperature or below. The melting point of the gelatin gel is totally dependent on its concentration and molecular weight (MW), but the upper melting point is below human body temperature (usually $<35^{\circ} \mathrm{C}$ ). ${ }^{15}$ In this study, we first prepared a $20 \% \mathrm{w} / \mathrm{v}$ gelatin solution in a mold at $37^{\circ} \mathrm{C}$ and then decreased the temperature to $4{ }^{\circ} \mathrm{C}$ to solidify the gelatin solution as a gelatin gel. After LBL deposition, the gelatin-substrated LBL nanomembrane was transferred to $37^{\circ} \mathrm{C}$ water for melting, and finally, a freestanding nanomembrane (floating in water) was obtained (Figure 1A-C and Video S1). Several synthetic biomaterials that are regarded as cell scaffolds have been explored and applied for cell culture in tissue engineering recently. It is generally necessary for biomimetic materials to be biocompatible, biodegradable, and non-cytotoxic. ${ }^{16} \mathrm{CHI}$ and ALG are widely used for biomedical applications because both exhibit favorable biocompatibility and non-cytotoxicity. ${ }^{17}$ $\mathrm{CHI}$ is a natural polysaccharide that is derived from sea crustaceans with unexceptionable biocompatibility and biodegradability that acts as a structural unit for cells. It is also used as an antimicrobial agent against methicillin-resistant Staphylococcus aureus, S. aureus, and Escherichia coli. ${ }^{18}$
ALG is a polyanion that has variable biocompatibility and preferable performance for cell encapsulation, cell transplantation, and wound healing. ${ }^{19,20}$ Recently, much research has been performed with the two biomaterials together. Accordingly, the LBL self-assembly technique provides an approach for fabricating CHI-ALG multilayer films. The amino group of $\mathrm{CHI}$ enables it to ionize to a polycation in water, which shows a natural attraction to ALG because the carboxyl group of ALG turns it into a polyanion in water simultaneously. This reaction creates the exact condition necessary for the integration of the two polyelectrolytes on a specific substrate via LBL self-assembly.

Bioactive scaffolds that work as extracellular matrices (ECMs) are usually affixed with cells to study their biocompatibility in vitro. ${ }^{21,22}$ Accordingly, we seeded the bone marrow stem cells (BMSCs) on the surface of the gelatinsubstrated $\mathrm{CHI} / \mathrm{ALG}$ nanomembrane and then transferred it into a $37^{\circ} \mathrm{C}$ incubator in which gelatin block gradually melted, and the cell-seeded and free-standing nanomembrane formed via this mild process (Figure 1D-G). Thus, the biocompatibility of the nanomembrane was studied in vitro. Mesenchymal stem cells (MSCs) have been widely adopted for wound-healing research in tissue engineering since their capability of differentiation and angiogenesis was developed in vivo. ${ }^{23}$ Inspired by a natural protocol, we seeded mouse BMSCs that were transduced with the green fluorescent protein (GFP) gene on the membrane and transplanted them to mouse dorsal skin that had a full-thickness defect. ${ }^{24}$ Skin injuries, such as burns, traumas, and ulcers that are derived from various chronic diseases often destroy the structure of skin tissues, resulting in wound exposure and the increased chance for bacterial invasion. ${ }^{25}$ Autologous skin grafting is a conventional therapeutic strategy for small skin damage. ${ }^{26}$ However, in cases of large skin loss, this method may be infeasible because of limited skin supply. Autologous skin grafting itself provides additional injury to normal skin. Allogeneic and xenogeneic skin substitutes have been considered for clinical use, but immune rejection by the host of allografts and xenografts remains a serious challenge that must be overcome. ${ }^{27,28}$

Skin tissue engineering technology plays a significant role under these circumstances. ${ }^{29}$ Engineered skin structural and functional tissue is formed via the creation of biomimetic scaffolds as an ECM to facilitate cell adhesion, migration, proliferation, and differentiation, which ultimately achieves skin reconstruction. ${ }^{30,31}$ This article shows that significantly higher survival and proliferation of the GFPBMSCs are achieved when the nanomembrane is applied on 
A

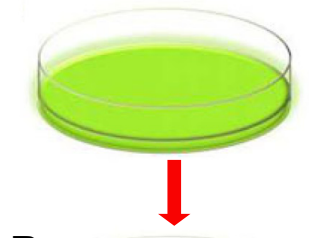

B
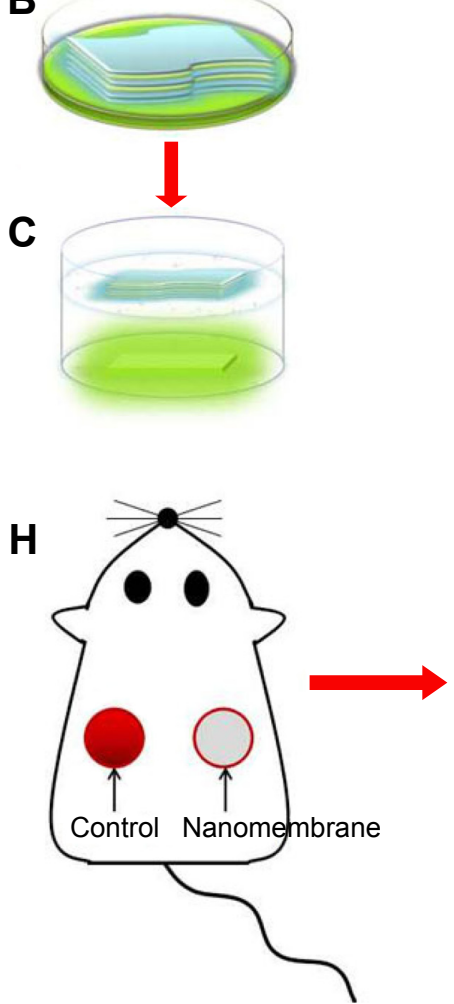

D
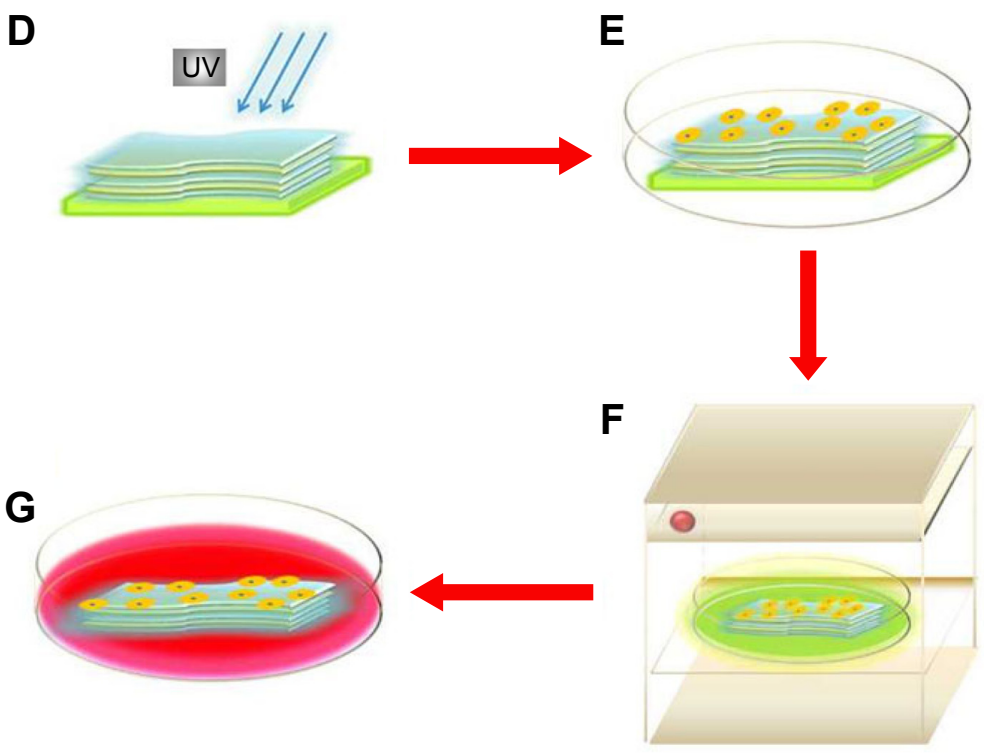

Control group: without nanomembrane. Both inject BMSCs. $\left.\begin{array}{l}\text { In vivo imaging } \\ \text { FACS } \\ \text { Frosen section }\end{array}\right\}$ Stem cell proliferation?

Wound healing assessment

H\&E staining: re-epithelialization and granulation hyperplasia?

Figure I Schematic illustration of the procedure for the fabrication of the CHI/ALG free-standing nanomembrane and the formation of the cell free-standing nanomembrane complex.

Notes: (A) Solidified gelatin solution as the substrate; (B) LBL deposition of CHI and ALG; (C) the CHI/ALG nanomembrane became free-standing as the substrate melted in $37^{\circ} \mathrm{C}$ water; (D) the gelatin-supported nanomembrane was sterilized with UV light for 2 hours before cell seeding; (E) the cells seeded on the surface of the complex; (F) the gelatin block gradually melted in the $37^{\circ} \mathrm{C}$ incubator; $(\mathbf{G})$ the cell free-standing nanomembrane formed; (H) graphical representation for the experiments.

Abbreviations: ALG, alginate; BMSCs, bone marrow stem cells; CHI, chitosan; FACS, fluorescence-activated cell sorting; H\&E, hematoxylin and eosin; LBL, layer by layer; UV, ultraviolet.

a skin wound. Therefore, this methodology provides a fast and safe approach for constructing free-standing biomimetic scaffolds for tissue engineering.

\section{Materials and methods Materials}

The CHI (85\% deacetylated; MW: 100,000) and gelatin (from porcine skin) were both purchased from Sigma-Aldrich Co. (St Louis, MO, USA). The ALG acid sodium salt (low viscosity) was purchased from Alfa Aesar (Ward Hill, MA, USA). The 7-aminoactinomycin D (7-AAD) was purchased from Thermo Fisher Scientific (Waltham, MA, USA), and 4',6diamidino-2-phenylindole and dihydrochloride were purchased from Beyotime Biotechnology (Shanghai, People's
Republic of China). We purchased 3-(4,5-dimethylthiazol2-yl)-2,5-diphenyltetrazolium bromide (MTT) from SigmaAldrich Co.

\section{Fabrication of the CHI/ALG nanomembrane}

Gelatin $(8 \mathrm{~g})$ was dissolved in deionized water $(40 \mathrm{~mL})$ in a $37^{\circ} \mathrm{C}$ water bath for 20 minutes to produce the $20 \% \mathrm{w} / \mathrm{v}$ gelatin solution. It was then transferred to a glass culture dish and maintained at $4{ }^{\circ} \mathrm{C}$ for 30 minutes for solidification. The solidified gelatin gel was used as the substrate for the LBL self-assembly. CHI and ALG acids (both $0.2 \mathrm{~g}$ ) were each separately dissolved in $40 \mathrm{~mL}$ of water, and $0.32 \mathrm{~g}$ of $\mathrm{NaCl}$ $(0.14 \mathrm{~mol} / \mathrm{L})$ was added to the two solutions. Acetic acid 
$(0.1 \mathrm{~mol} / \mathrm{L})$ was added to the $\mathrm{CHI}$ solution to accelerate the dissolution. $\mathrm{NaOH}$ solution $(0.1 \mathrm{~mol} / \mathrm{L})$ was used to change the ALG acid to a salt. Finally, the $\mathrm{pH}$ of the CHI solution was adjusted to 5.0 with a $\mathrm{NaOH}$ solution $(0.1 \mathrm{~mol} / \mathrm{L})$.

The concretionary gelatin gel was washed with distilled water at room temperature twice before coating. First, the gelatin substrate was immersed in the $\mathrm{CHI}$ solution for 7 minutes in the dish, and then it was rinsed with deionized water for 1 minute. Subsequently, it was dipped in the ALG solution for another 7 minutes followed by rinsing in deionized water for 1 minute. A cycle consisting of all of these steps was repeated until the expected number of deposited layers (15 layers) was achieved. The entire procedure was performed at room temperature $\left(20^{\circ} \mathrm{C}\right)$. After all the LBL assembly procedures were performed, the solid gelatin gel substrate was removed from the culture dish and cut into small pieces. It was then transferred to $37^{\circ} \mathrm{C}$ distilled water. The free-standing nanomembrane was released from the surface of the substrate and floated up in the water as the solid gelatin gradually melted.

\section{Scanning electron microscopy}

The nanomembrane was fixed with $4 \%$ paraformaldehyde for 1 hour on a clean glass slide. Then, it was washed with phosphate-buffered saline (PBS) three times and freeze-dried in a $-20^{\circ} \mathrm{C}$ freezer for 4 hours. The sample was then fixed on a silica wafer and coated with gold via Denton Desk II Sputtering. The morphology of the nanomembrane with the $\mathrm{CHI}$ on the outer layer was observed using scanning electron microscopy (SEM; Cambridge Stereoscan 120).

\section{Sample preparation for transmission electron microscopy}

The gelatin-supported nanomembrane was fixed for 3 hours with $3 \%$ glutaraldehyde in $0.1 \mathrm{M}$ Sorensen's buffer. The fixative was removed using a pipette and replaced with $5 \%$ sucrose in $0.1 \mathrm{M}$ Sorensen's buffer. On the second day, the buffer was replaced with $1 \%$ osmium tetroxide $\left(\mathrm{OsO}_{4}\right)$ in $0.1 \mathrm{M}$ Sorensen's phosphate buffer for 2 hours. The samples were then dehydrated using graded concentrations of ethanol (30\% for 10 minutes, $50 \%$ for 10 minutes, $70 \%$ for 10 minutes, $90 \%$ for $2 \times 10$ minutes, $100 \%$ for $3 \times 10$ minutes) and, finally, using $100 \%$ methanol for 20 minutes. The dehydrated samples were incubated in propylene oxide (PO) for 10 minutes. After removing the PO, 50\% Epon $/ 50 \%$ PO was added, and the solution was rotated at room temperature for 3 hours. Once complete, the mixture was removed, and 100\% Epon was added into the desired molds for 24 hours. On the third day, the sample was heated in a $60^{\circ} \mathrm{C}$ oven for 24 hours. Afterward, the sample block was complete and could be stored at room temperature until needed.

\section{Contact angle testing}

Different layers (from layers 1 to 10) of free-standing CHI/ALG nanomembranes were constructed. When they achieved freestanding status, they were moved onto sterilized glass slides. The water contact angles of each layer were measured using a contact angle measuring machine (rame-hart [Beijing United Test Technology, Beijing, People's Republic of China]).

\section{Cell culture in vitro}

BMSCs were obtained from C57BL female mice (100 g). After LBL deposition, the solid gelatin gel substrate with the (CHI/ALG) $)_{7}-\mathrm{CHI}$ nanomembrane on the surface was washed with PBS twice. BMSCs were seeded onto the surface of the unreleased film that had a solid substrate and placed in a $37^{\circ} \mathrm{C}$ incubator. The solid gelatin melted and released the nanomembrane with the BMSCs in the dish in $<1$ hour. After removing the melted gelatin, the cells were cultured with Dulbecco's Modified Eagle's Medium (Lonza, Walkersville, MD, USA) that was supplemented with $10 \%$ fetal bovine serum (HyClone, Logan, UT, USA) and 1\% penicillin/ streptomycin (Cellgro, Herndon, VA, USA).

Live/dead viability/cytotoxicity staining was used to test the vitality of the cells on the free-standing nanofilm after 3 days in culture. The membrane with the BMSCs was first rinsed with PBS three times ( 2 minutes each time). Calcein acetoxymethyl ester $(2 \mu \mathrm{L})$ and $\mathrm{EthD}^{-1}(4 \mu \mathrm{L})$ in PBS were added. After incubating at $37^{\circ} \mathrm{C}$ for 10 minutes, the cell-nanomembrane sample was observed using an Inverted Fluorescence Microscope (modelIX70; Olympus Corporation, Tokyo, Japan).

The morphologies of the MSCs on the membrane were also observed using SEM. After culturing for 3 days, the adhered cells and membranes were fixed with $2.5 \%$ glutaraldehyde and subjected to a series of graded alcohol-water solutions $(25 \%, 50 \%, 75 \%, 95 \%$, and $100 \%)$. After drying and sputter coating with $\mathrm{Au}$, the samples were observed using SEM.

\section{MTT assay}

After sterilization, the nanomembrane was transferred to 96-well plates. The BMSCs $\left(20 \mu \mathrm{L}\right.$ at $\left.5.0 \times 10^{5} / \mathrm{mL}\right)$ were seeded on the nanomembrane and in a blank 96-well plate. The culture media was exchanged every 24 hours. The MTT $(5 \mathrm{mg} / \mathrm{mL})$ solution was prepared in PBS. Approximately $20 \mu \mathrm{L}$ of MTT reagent was added to each well. Afterward, the plate was incubated in a $37^{\circ} \mathrm{C} / 5 \% \mathrm{CO}_{2}$ incubator. The medium was removed carefully 4 hours later; then, $200 \mu \mathrm{L}$ of dimethyl sulfoxide was added to each well. The plates were 
returned to the incubator for another 10 minutes. Finally, the mixed solution was transferred to a new 96-well plate at each test time. The absorbance of the solution was measured using an Au Quant Microplate Reader (BioTek Instruments Inc., Winooski, VT, USA) at $595 \mathrm{~nm}$.

\section{In vivo test}

The animal experiments were performed with the approval of the Animal Ethics Committee of the Third Military Medical University (TMMU, Chongqing, People's Republic of China). All animal experiments were performed in accordance with the Third Military Medical University's animal experiment guidelines. Seven- to eight-week-old BALB/c mice were purchased from the Laboratory Animal Center at TMMU. After anesthesia by intraperitoneal injection of sodium pentobarbital $(100 \mathrm{mg} / \mathrm{kg})$, a $5 \mathrm{~mm}$ diameter full-thickness cutaneous defected wound was created on the depilated dorsal skin in each of the eight mice. The mice were randomly divided into two groups (four in each group). After sterilizing with iodophor and $70 \%$ ethyl alcohol, the wounds were covered with the CHI/ALG nanomembrane for the experimental group, and Vaseline gauze was used for the control group. Five million BMSCs that were transduced with the GFP gene were transplanted to the periphery of the skin wound of each mouse via subcutaneous injection. Then, the nanomembrane and Vaseline gauze were fixed with surgical tape. The GFP-expressing cells on each model of the two groups were recorded with in vivo imaging (Maestro EX) on day 7 post transplantation.

\section{GFP-BMSC analysis via fluorescence- activated cell sorting}

On day 7 , the wound tissues were minced into small pieces and digested in $0.5 \%$ trypsin at $37^{\circ} \mathrm{C}$ for 10 minutes. The digestion was stopped by adding a double amount of culture medium. Then, the wound cell suspension was filtered and centrifuged at $1,000 \mathrm{rpm}$ for 10 minutes at $4{ }^{\circ} \mathrm{C}$. The cell pellet was resuspended in $500 \mu \mathrm{L}$ of PBS. The number of cells was counted with $10 \mu \mathrm{L}$ of the suspension on a cell-counting chamber after the addition of 7-AAD dye (1:500) for 10 minutes at room temperature. The remaining samples were used for detecting the GFP-positive cells on a fluorescence-activated cell sorting (FACS) sorter (Attune acoustic focusing cytometer).

\section{Immunofluorescence}

Frozen sections $(8 \mu \mathrm{m})$ of the wound tissue were prepared on day 7 after surgeries on each group. The sections were maintained in air at room temperature for 10 minutes and then fixed with acetone at $4^{\circ} \mathrm{C}$ for 10 minutes. After washing in PBS three times (5 minutes each), the sections were blocked with $1 \%$ bovine serum albumin for 1 hour, followed by a primary antibody against GFP (1:200) overnight at $4^{\circ} \mathrm{C}$. The sections were then rinsed in PBS three times ( 5 minutes each) and added to the secondary antibody (fluorescein isothiocyanate: $1: 100)$. After incubation at $37^{\circ} \mathrm{C}$ for 1 hour, the sections were washed in PBS and stained with 4',6-diamidino-2-phenylindole for 10 minutes. After the final washing in PBS, the sections were cover slipped with an anti-fade mounting medium and examined under the Inverted Fluorescence Microscope (model IX70).

\section{Wound-healing experiment}

To evaluate how the $\mathrm{CHI} / \mathrm{ALG}$ nanomembrane promoted would healing with the BMSCs, BALB/c mice were distributed into four groups (eight in each group). There were the blank control group, the nanomembrane group, the BMSC-injected group, and the nanomembrane + BMSCinjected group. While under anesthesia with $1 \%$ pentobarbital via intraperitoneal injection $(100 \mathrm{mg} / \mathrm{kg})$, a $5 \times 5 \mathrm{~mm}$ full-thickness dorsal cutaneous defected wound was created on each mouse using the same method mentioned earlier. Then, the BMSC subcutaneous injections were performed only on the BMSC-injected group and the nanomembrane + BMSC-injected group. The wounds were immediately photographed using a digital camera. This was also performed on day 1 , day 3 , day 5 , day 7 , and day 9 post surgery. The initial or left areas of the wounds were measured with Image Pro Plus 6.0 software using the pictures. The condition of wound healing in each group was observed and assessed at different times after surgery using the following formula:

$$
\text { Percentage of the residual wound }=\frac{\mathrm{AW}_{n}}{\mathrm{AW}_{\mathrm{i}}} \times 100 \%
$$

where $\mathrm{AW}_{n}$ is the area of the wound on the $n$th day post surgery and $\mathrm{AW}_{\mathrm{i}}$ represents the area of the initial wound..$^{32}$

\section{Hematoxylin and eosin staining and analysis}

The mice wound tissues were obtained at every photographed time point and stained with hematoxylin and eosin for histological analysis. The tissues were first fixed with $4 \%$ formaldehyde, then embedded in paraffin, and finally sectioned at a thickness of $5 \mu \mathrm{m}$. The length of the newly formed epithelium was measured with Image Pro Plus 6.0 software, and the measurement procedure was performed by two blinded pathologists. The length of the epithelial tongue was defined as the distance between the advancing edges of 
the epidermal keratinocytes and the presence of hair follicles in the normal skin tissue. Five sections from five mice from each group at each time point were analyzed.

\section{Results and discussion}

A relatively high concentration $(20 \% \mathrm{w} / \mathrm{v})$ of gelatin solution was produced to make sure that the substrate is robust enough and easy to solidify. The gelatin block could be cut into whatever shapes we want as a substrate. The LBL selfassembly should be carefully handled during the process of coating because the integrity of the nanomembrane may be damaged in a careless surgery. All the coating steps need to be performed on a gelatin substrate in an ice bath.

The coating job to produce the desired layers (we fabricated 15 layers) was accomplished with a layer of $\mathrm{CHI}$ ending for cell adhesion, because the cells have negative charges on the surface of the membrane. The simple but key action to free the nanomembrane was performed after all the depositing tasks.

The gelatin substrate and deposited (CHI/ALG) $)_{7}-\mathrm{CHI}$ nanomembrane was moved into a medium at a temperature of $37^{\circ} \mathrm{C}$; subsequently, the gelatin gels gradually melted in a few minutes, followed by the release of the free-standing CHI/ALG nanomembrane that floated up in the water (Video S1). After acquiring the free nanomembrane, it was kept in PBS buffer or medium to preserve its bioactivity (Figure 2A). SEM showed the two-dimensional structure of the CHI-ending surface. It had a pyknotic and unsmooth ground with irregular concave-convex structures (Figure 2B).

The water contact angles on different layers with either the $\mathrm{CHI}$ ending or the ALG ending were tested to confirm that the LBL self-assembly occurred on the gelatin substrate and to investigate the hydrophilic property of the different layers of the nanomembrane. ${ }^{12}$ The contact angles of layer 1 to layer 10 were all tested to determine the differences. As shown in Figure $2 \mathrm{C}$, the average contact angles varied from layer to layer. The angles of all the $\mathrm{CHI}$-ending layers (odd-numbered layers) were consistently at $\sim 60^{\circ}$ on average, whereas those of the ALG-ending layers (even-numbered layers) were consistently at $\sim 50^{\circ}$, indicating successful LBL deposition. Noticeably, the ALG was much more hydrophilic in comparison to the CHI, as evidenced by its smaller water contact angles.

Transmission electron microscopy was utilized to study the nanostructure of the membrane on the gelatin substrate. After dehydration with different concentrations of ethanol
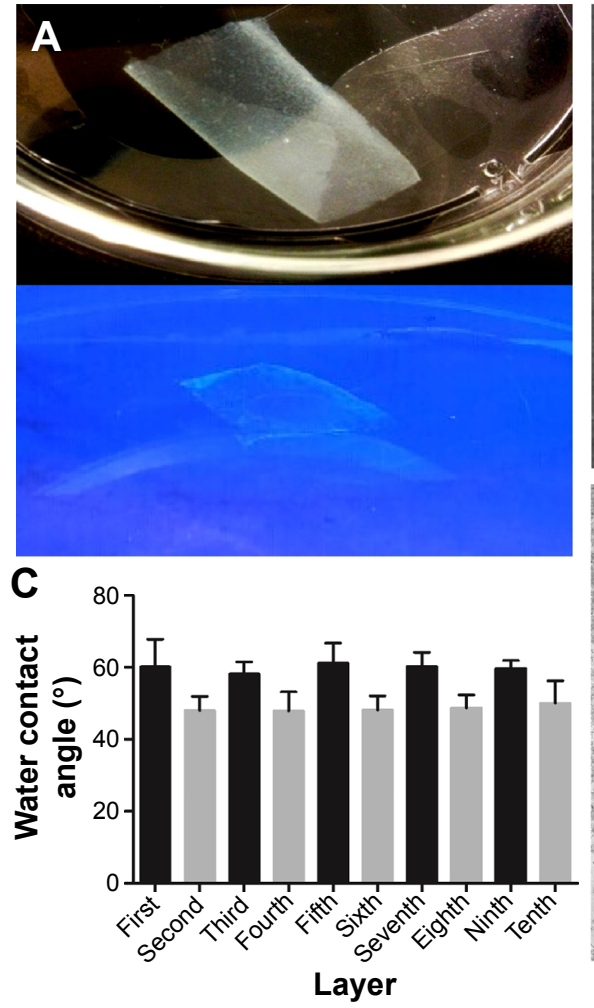
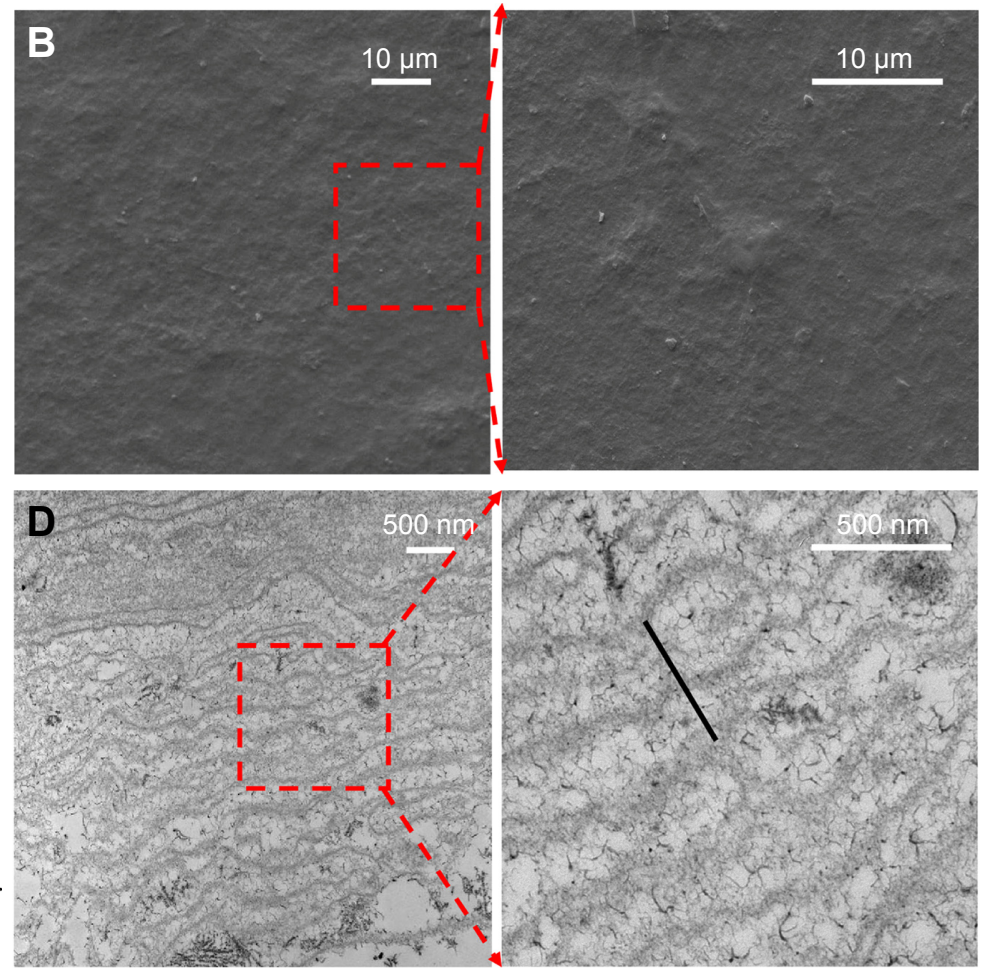

Figure 2 Observation of the free-standing CHI/ALG nanomembrane.

Notes: (A) Free-standing CHI/ALG nanomembrane floating in PBS buffer (top) under UV light (below); (B) SEM of the nanomembrane. Scale bar: I0 $\mu$ m. (C) Water contact angles of the different layers; (D) TEM of the nanomembrane. The thickness between two adjacent layers was $\sim 200 \mathrm{~nm}$ (as indicated by the black bar), and the entire thickness was proportional to the number of deposited layers. Scale bar: $500 \mathrm{~nm}$.

Abbreviations: ALG, alginate; CHI, chitosan; PBS, phosphate-buffered saline; SEM, scanning electron microscopy; TEM, transmission electron microscopy; UV, ultraviolet. 
from $30 \%$ to $100 \%$, the $(\mathrm{CHI} / \mathrm{ALG})_{7}-\mathrm{CHI}$ nanomembrane was cut into small pieces and then observed using transmission electron microscopy. The LBL three-dimensional (3D) structure in the nanoscale was clearly demonstrated. There was $\sim 200 \mathrm{~nm}$ between two adjacent layers, and the overall thickness of the membrane was $\sim 3,750-7,500 \mathrm{~nm}$. Meanwhile, the entire thickness was in direct proportion to the number of layers (Figure 2D).

The live/dead assay of the BMSCs evaluated the biocompatibility of the $\mathrm{CHI} / \mathrm{ALG}$ nanomembrane. As shown in Figure $3 \mathrm{~A},>99 \%$ of the BMSCs had a healthy appearance after 3 days in culture. The several dividing BMSCs on the nanomembrane were an indication of its excellent biocompatibility. Cells cultured on the CHI/ALG nanomembrane and on the blank 96-well plates were tested for their viability using the MTT assay. The absorbance of the two groups at different time points represented the total number of viable cells. As illustrated in Figure 3B, there was no significant difference between the two groups at 0 hour, 24 hours, and
48 hours, but a significant increase at 72 hours for the cells on the $\mathrm{CHI} / \mathrm{ALG}$ nanomembrane was observed, indicating that the free-standing nanomembrane promoted cell proliferation. Meanwhile, the morphologies of the cells on the membrane were also observed under SEM, and it was also confirmed that the MSCs could adhere on the membrane. The MSCs showed spread morphologies with filopodia (Figure 3C). This suggests that the nanomembrane provides excellent adhesion to the cells. It is likely that the floating nanomembrane also allowed the cells to have better (3D) access to nutrients in the culture medium.

The biocompatibility of the nanomembrane was also tested in vivo. BMSCs that stably express the GFP gene were transplanted to the periphery of the skin wound in each mouse via subcutaneous injection. In vivo imaging of each mouse in the two groups showed a significant difference in survival and growth of the GFP-BMSCs between the control group and experimental group at 7 days post surgery. As shown in Figure 4A and B, the fluorescent intensity in the
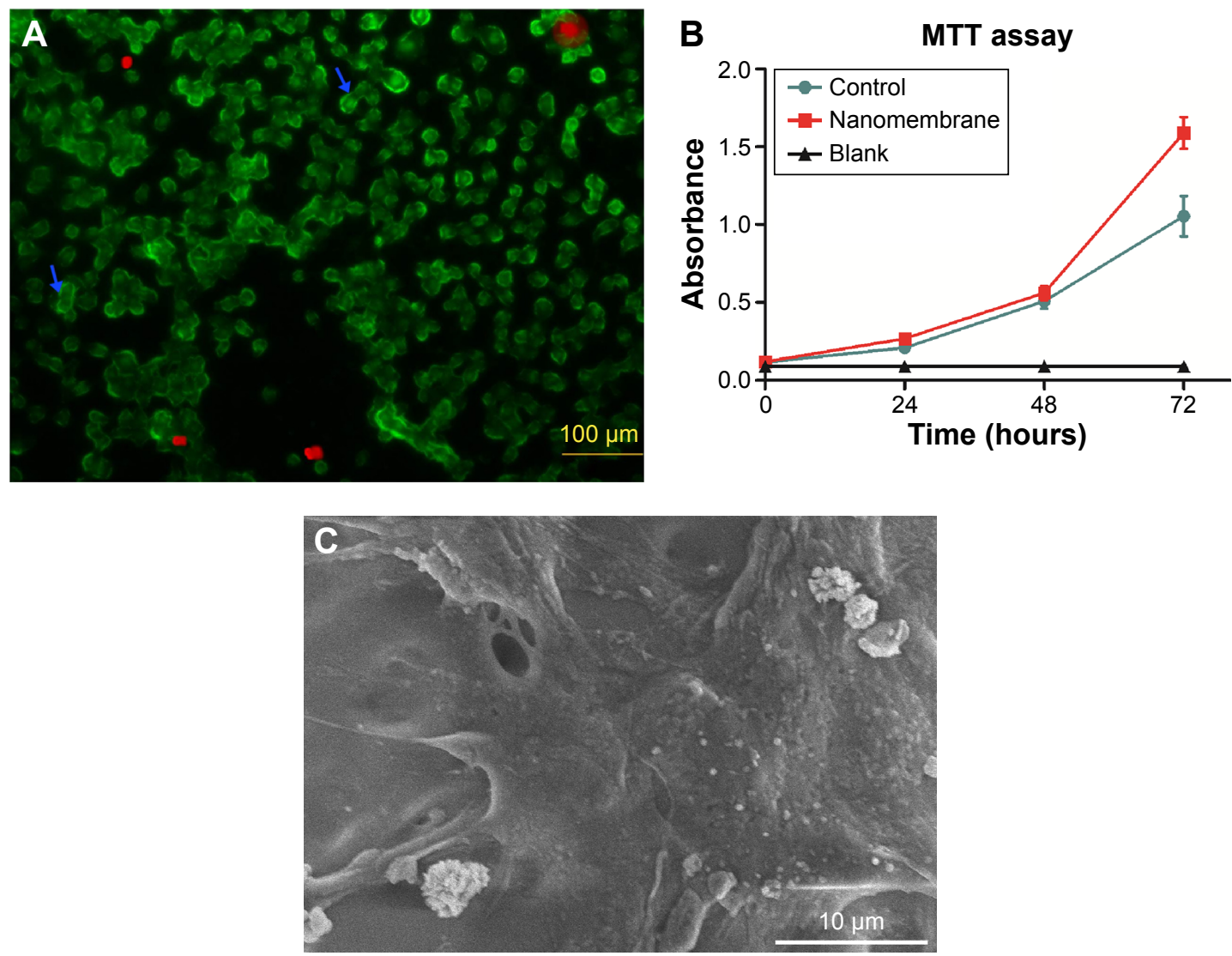

Figure 3 Cell adhesion and proliferation on the membrane.

Notes: (A) Live/dead assay of the BMSCs that were cultured on the CHI/ALG free-standing nanomembrane after 3 days. The arrows represent the dividing cells. Scale bar: $100 \mu \mathrm{m}$. (B) MTT assay of cells culturing on the nanomembrane and 96-well plate at 0 hour, 24 hours, 48 hours, and 72 hours; (C) SEM image of the MSCs that were cultured on the nanomembrane after 3 days. Scale bar: $10 \mu \mathrm{m}$.

Abbreviations: ALG, alginate; BMSCs, bone marrow stem cells; CHI, chitosan; MSCs, mesenchymal stem cells; MTT, 3-(4,5-dimethylthiazol-2-yl)-2,5-diphenyltetrazolium bromide; SEM, scanning electron microscopy. 


\section{A}
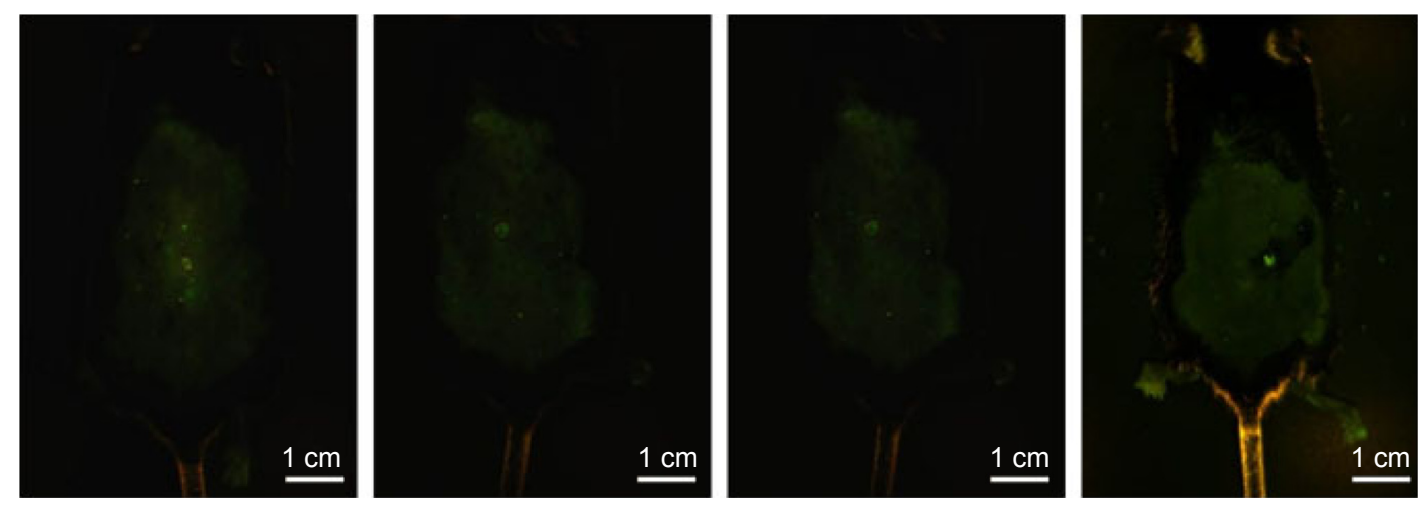

B
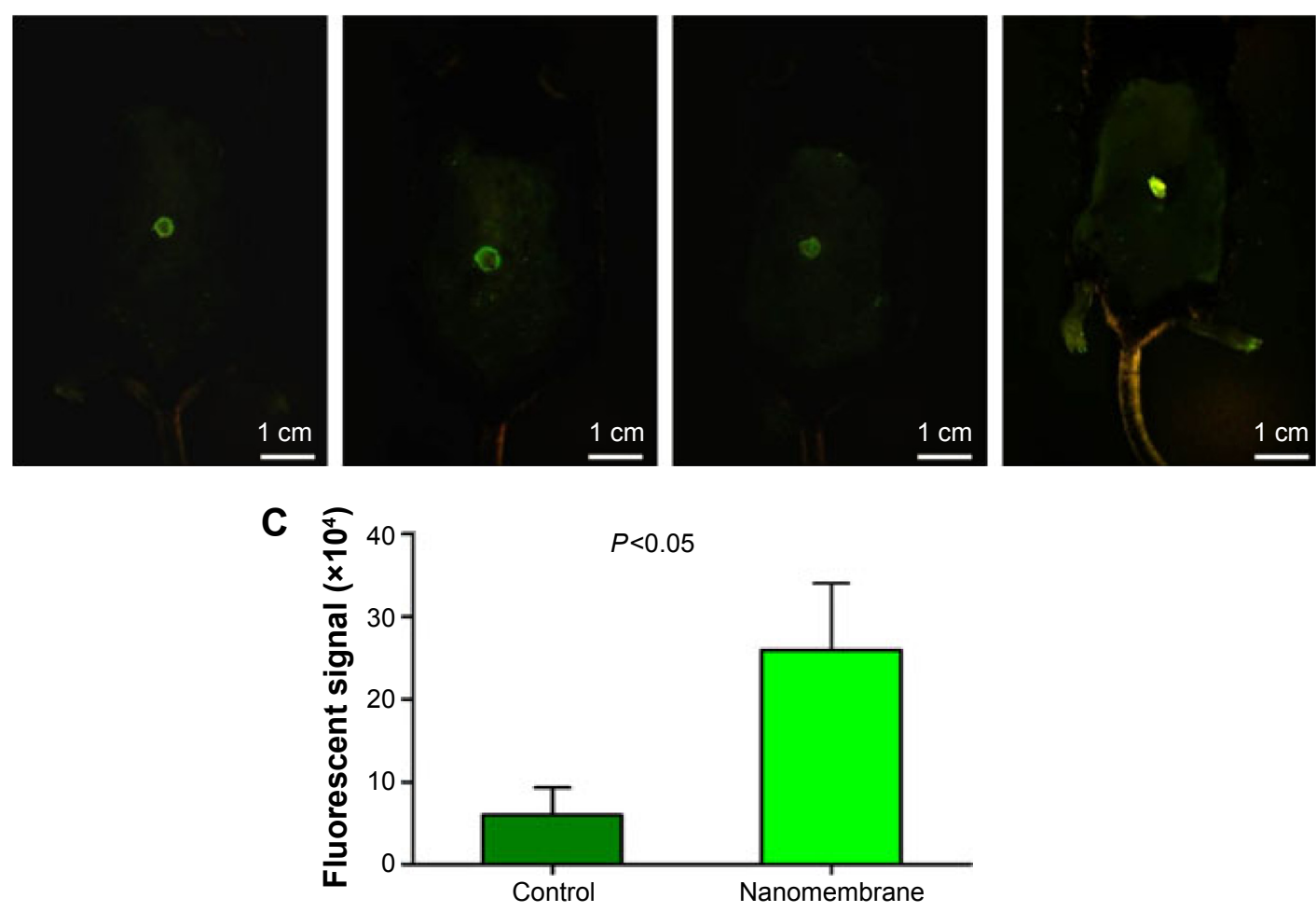

Figure 4 In vivo images of the GFP-MSCs on the mouse dorsal skin wounds.

Notes: (A) Fluorescent signal of the GFP-MSCs in the control group at day 7; (B) fluorescent signal of the GFP-MSCs in the experimental group at day 7. Scale bar: I $\mathrm{cm}$. (C) Fluorescent signal quantification: the average signal intensity in the control group was $6.00 \pm 2.84\left(\times 10^{4}\right)$, whereas in the nanomembrane group, it was $25.97 \pm 6.98\left(\times 10^{4}\right)$. $P<0.05$.

Abbreviations: GFP, green fluorescent protein; MSCs, mesenchymal stem cells.

central part of the wound was stronger in the nanomembrane group, which suggests that the nanofilm may accelerate cell migration from the edge to the middle of the wounds. The total intensity of the GFP signal of the nanomembrane group was significantly higher than in the control group (Figure 4C). The average signal intensity in the control group was $6.00 \pm 2.84\left(\times 10^{4}\right)$, whereas in the experimental group, it was $25.97 \pm 6.98\left(\times 10^{4}\right), P<0.05$.

The FACS analysis of the GFP-positive MSCs that were harvested from the wounds provided direct evidence for the survival of the transplanted cells. On days 5 and 7 after cell transplantation, equal amounts of tissue from each mouse were collected on the skin wound that received 5 million GFP-BMSCs. Single-cell suspensions that were prepared from the wound tissues were subjected to the FACS analysis for the GFP-positive cells. Because we expected that the suspensions would contain not only the transplanted GFP-positive cells and non-GFP-positive cells but also dead cells, we used 7-AAD labeling for dead cell exclusion. The results showed that the ratio of living GFP-BMSCs to all living cells on day 5 was $33.58 \%$ in the control group and $66.78 \%$ in the experimental group, and $33.45 \%$ and $53.03 \%$ on day 7 , respectively (Figure 5). The statistical analysis of the data indicated that the CHI/ALG nanomembrane significantly enhanced the survival of the transplanted cells. 

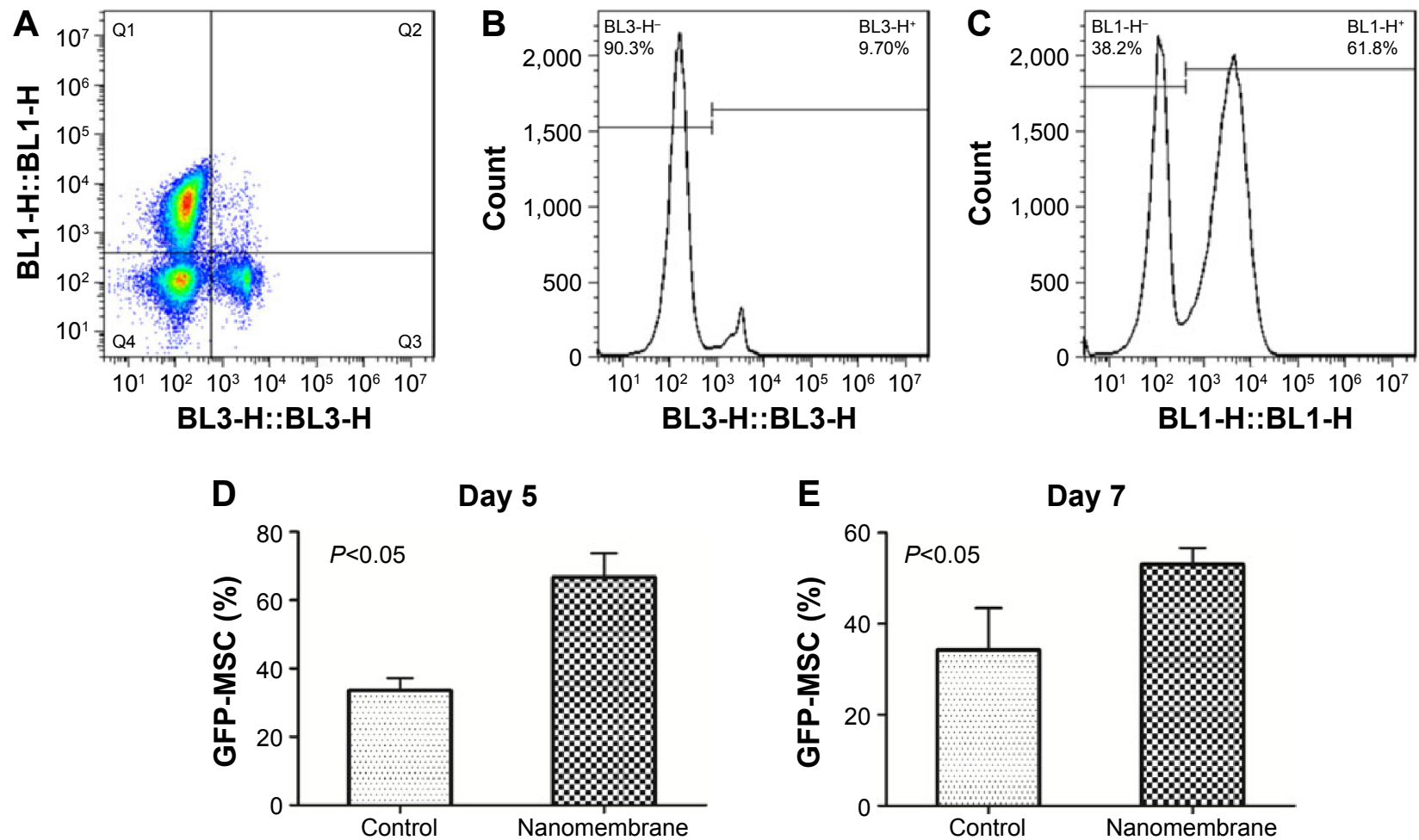

Figure 5 Positive GFP-MSC ratio detection using FACS.

Notes: (A) BLI and BL3 represented the two different markers for GFP and 7-AAD, respectively. QI: GFP+ and 7-AAD: living GFP-MSCs; Q2: GFP+ and 7-AAD': dead GFP-MSCs; Q3: GFP- and 7-AAD': dead non-GFP cells; Q4: GFP- and 7-AAD': living non-GFP cells; (B) percentage of living cells detected by FACS: QI + Q4/QI + Q2 + Q3 + Q4 × 100\%; (C) percentage of positive GFP-MSCs in the living cells: QI/QI + Q4 × 100\%; (D) and (E) average percentage of positive GFP-MSCs in all the living cells in the two groups at days 5 and 7 post surgery.

Abbreviations: FACS, fluorescence-activated cell sorting; GFP, green fluorescent protein; MSCs, mesenchymal stem cells; 7-AAD, 7-aminoactinomycin D.

Morphological analysis further confirmed the increased survival of the transplanted GFP-BMSCs. The wound tissues that were collected on day 7 after the transplantation contained more GFP-BMSCs in the nanomembrane group compared to the control group (Figure 6A and B). Four images with the same scale and size $(750 \times 500 \mu \mathrm{m})$ in each group were randomly selected to count the number of GFP-BMSCs. As shown in Figure 6C, the average amount of green fluorescent cells in the control group was $25.25 \pm 5.07$, whereas in the nanomembrane group, it was $101.00 \pm 15.51, P<0.05$. The results directly indicate that the CHI/ALG nanomembrane positively enhanced the delivery and growth of the BMSCs in vivo.

For the different processing conditions in the mice woundhealing models, the wounds of the nanomembrane + BMSCs group showed a significantly faster healing speed than the other three groups (Figure 7A-D). In addition, the BMSCs and the nanomembrane group also achieved better wound healing than the control group. The speed of wound healing in each group was not consistent with the entire time because of the potential wound contraction at the very early time points (day 1 and day 3); however, in the last phase of wound healing (after day 7), the difference in every group was clear. The ratio of the left wound in the control group was larger than the others, whereas the ratio in the nanomembrane + BMSCs group was the smallest. In addition, there was no significant difference between the nanomembrane group and the BMSCs group (Figure 7E). Then, we measured the length of the newly formed epithelium and the thickness of the new granulation tissue based on the hematoxylin and eosin staining sections. At day 7 , the length of the newly formed epithelium was significantly increased in the nanomembrane + BMSCs group compared with the control, nanomembrane, and BMSC groups. In addition, the granulation tissue in the nanomembrane + BMSCs group and in the BMSC group was both thicker than in the control group (Figure 8), which suggests that the nanomembrane and BMSCs may promote granulation hyperplasia. Enhanced reepithelialization may result from more BMSC proliferation, migration, and differentiation with the nanomembrane that played a role as the ECM. Thus, the nanomembrane enhanced wound healing with stem cells. In this way, cells and cell scaffolds, as two of the essential factors of tissue engineering, worked inter-coordinately to obtain the best benefit.

\section{Conclusion}

An ultrathin 3D CHI/ALG nanomembrane was fabricated using the extremely convenient but safe method of LBL 

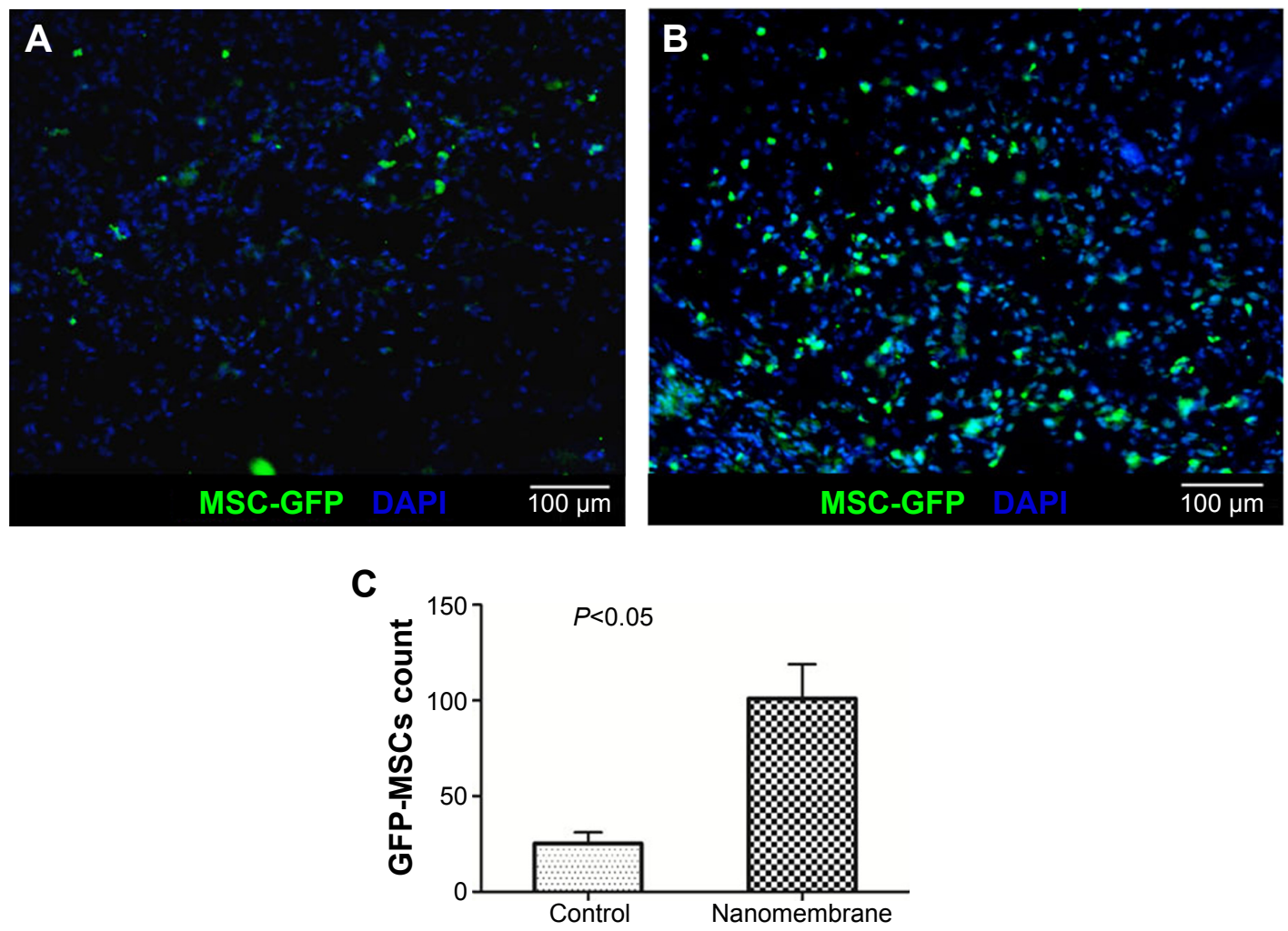

Figure 6 Observation of the frozen sections.

Notes: (A) Engraftment of the GFP-MSCs into the wounds of the control group; (B) engraftment of the GFP-MSCs into the wounds of the nanomembrane group. Both tissue sections of the wounds in the two groups were immunostained with an antibody against GFP at day 7 after surgery. MSC-GFPs (green) were engrafted into the newly formed tissue. The nuclei were stained with DAPI (blue). Scale bar: $100 \mu \mathrm{m}$. (C) Average GFP-MSC counts for the two groups. $P<0.05$.

Abbreviations: DAPI, 4',6-diamidino-2-phenylindole; GFP, green fluorescent protein; MSC, mesenchymal stem cell.

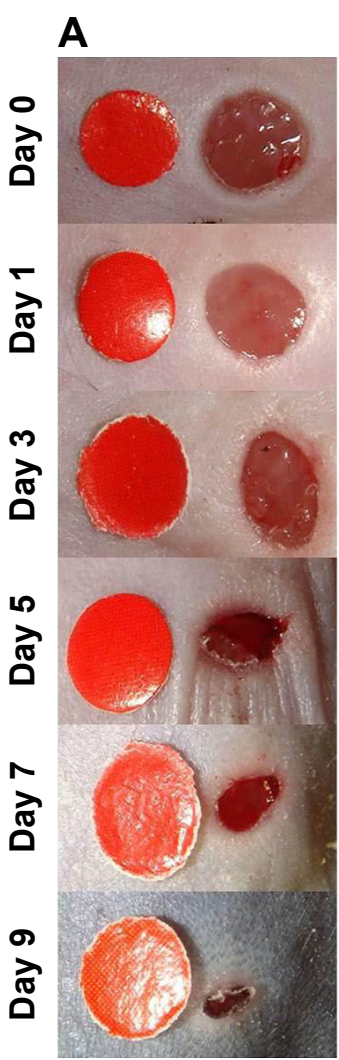

B

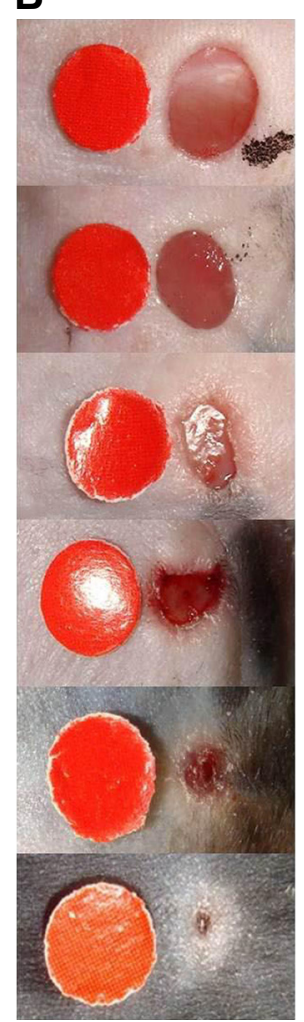

C

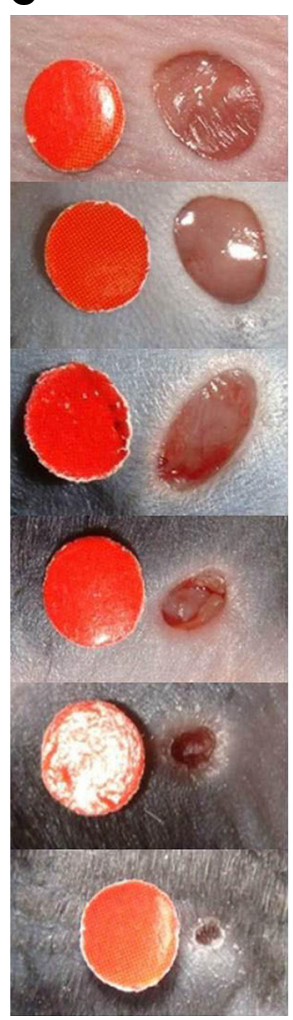

D

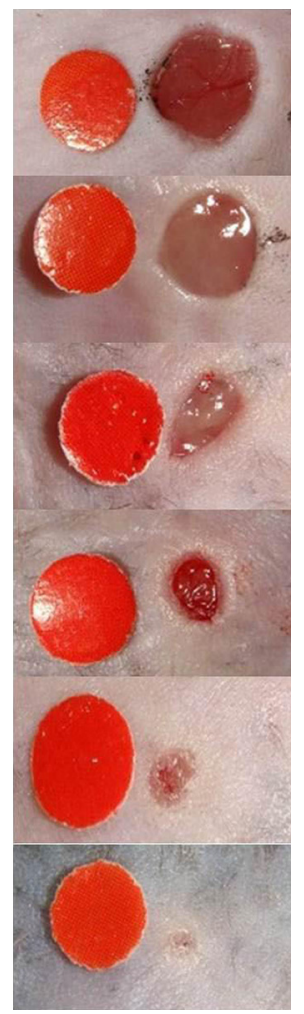

Figure 7 (Continued) 


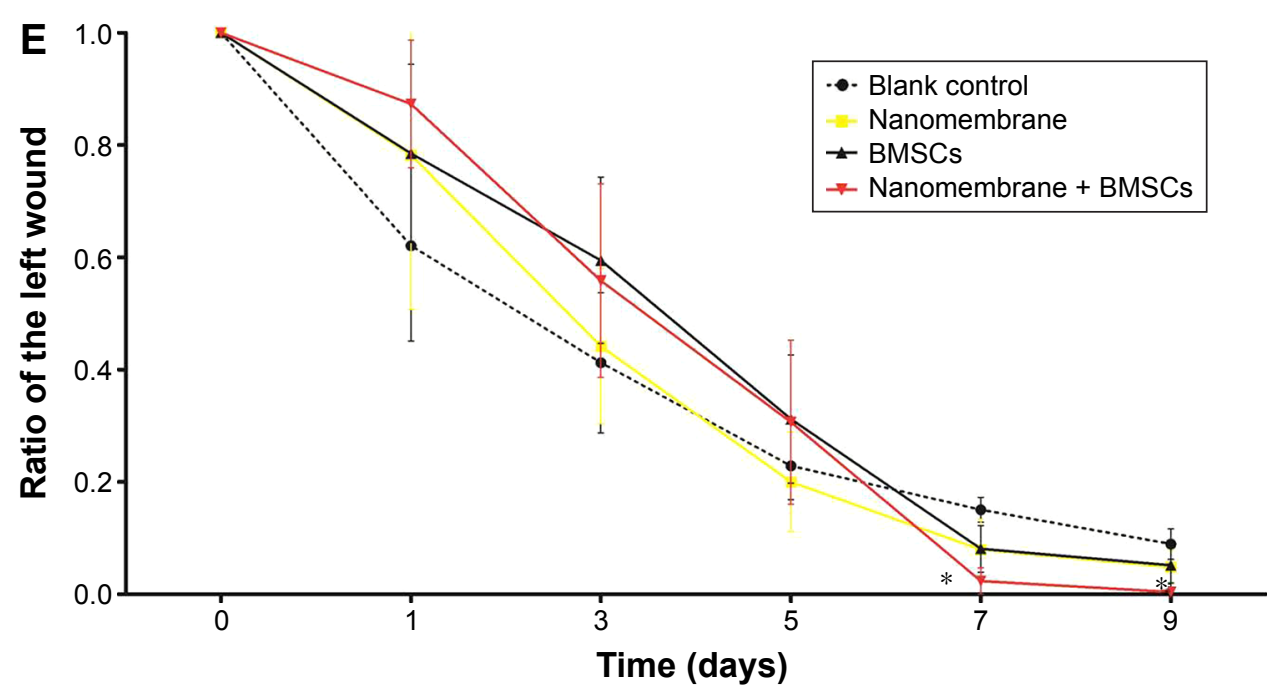

Figure 7 The macroscopic appearance of the wounds in the four groups at different time points post surgery.

Notes: (A) Control; (B) nanomembrane; (C) BMSCs; and (D) nanomembrane + BMSCs group; (E) the ratio of the left wound in every group at different time points from day 0 to day 9 . *Indicates that the $P$-value was less than 0.05 .

Abbreviation: BMSCs, bone marrow stem cells.

A
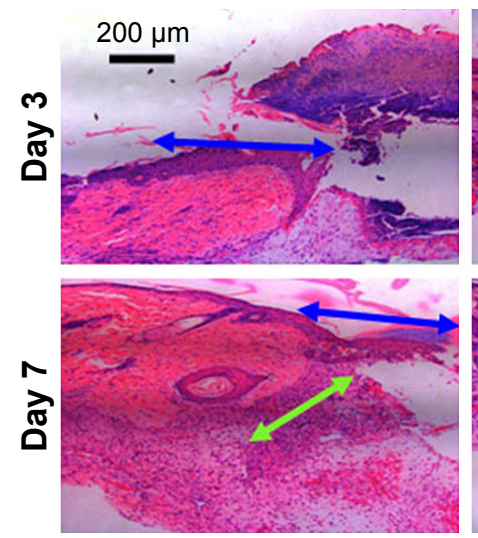

E

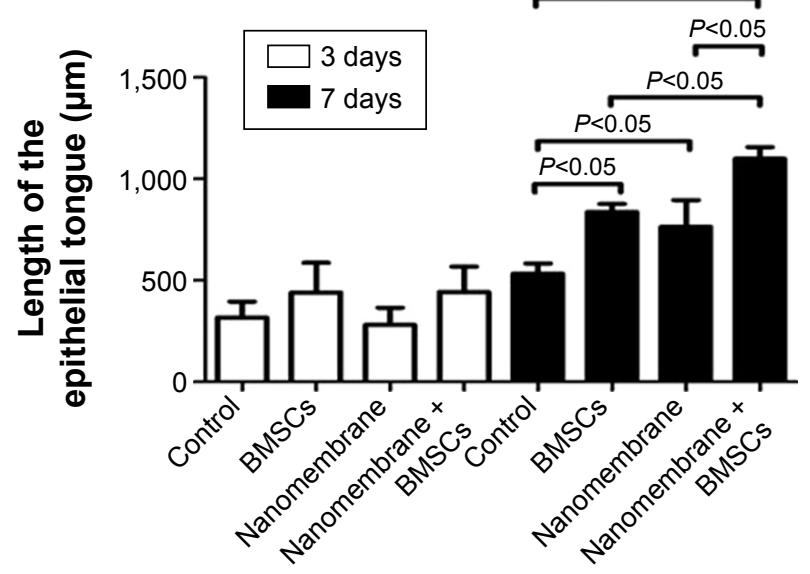

C
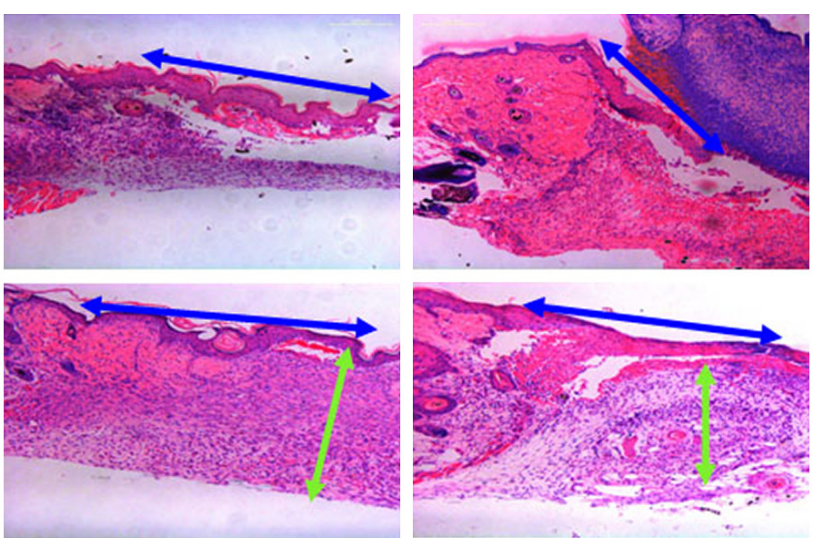

F

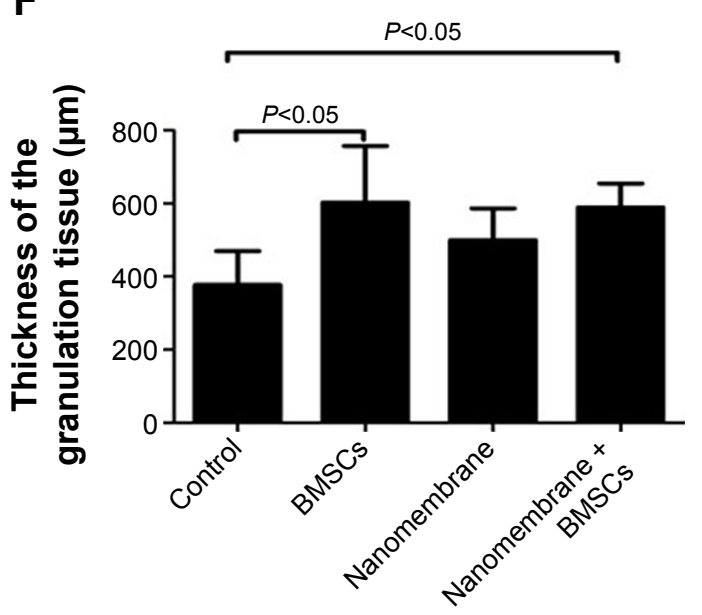

Figure 8 Length of the newly formed epithelium and the thickness of the granulation tissue post surgery.

Notes: (A) Control; (B) BMSCs; (C) nanomembrane; (D) nanomembrane + BMSCs; (E) the length of the epithelium tongue in each group at days 3 and 7; (F) the thickness of the granulation tissue in each group at day 7 . Values are the mean $\pm S D(n=5)$. The blue arrow indicates the length of the epithelium tongue and the green arrow indicates the thickness of the granulation tissue.

Abbreviation: BMSCs, bone marrow stem cells. 
self-assembly. The gelatin we used is superior to any other biomaterials as a substrate for LBL self-assembly not only because of its admirable biocompatibility but also because it can act as a sacrificial template that liberates the nanomembrane totally free-standing via a mild methodology. The entire fabrication process is time saving and material saving, and it vastly decreases the mechanical harm for the nanomembrane during liberation. The cell culture in vitro provided evidence that the fabricated nanomembrane is an excellent cell adhesive with unexceptionable biocompatibility. Playing the role of ECM, this nanomembrane serves as an excellent microenvironment for cell adhesion, migration, proliferation, and differentiation. An in vivo experiment with this nanomembrane was also conducted, showing that it has a great capability for stem cell delivery for skin tissue reconstruction. Certainly, many prospects for the nanomembrane can be expected in tissue engineering for clinical application in the future.

\section{Acknowledgments}

This work was supported by the Manitoba Institute of Child Health and China 863 Project (Grant No 2012AA020504) of the Institute of Burn Research, Southwest Hospital, the TMMU. MMQX would like to thank NSERC, Doctor Moorehouse Fellowship, and Manitoba Diabetes Foundation for the research support.

\section{Disclosure}

No competing financial interests exist for the authors. The authors report no conflicts of interest in this work.

\section{References}

1. Castleberry SA, Li W, Deng D, Mayner S, Hammond PT. Capillary flow layer-by-layer: a microfluidic platform for the high-throughput assembly and screening of nanolayered film libraries. ACS Nano. 2014;8(7): 6580-6589.

2. Decher G, Hong JD, Schmitt J. Buildup of ultrathin multilayer films by a self-assembly process: III. Consecutively alternating adsorption of anionic and cationic polyelectrolytes on charged surfaces. Thin Solid Films. 1992;210-211(pt 2):831-835.

3. Fujie T, Okamura Y, Takeoka S. Ubiquitous transference of a freestanding polysaccharide nanosheet with the development of a nanoadhesive plaster. Adv Mater Deerfield. 2007;19(21):3549-3553.

4. Gao S, Yuan D, Lü J, Li T, Cao R. Multilayer films of single-component and charged tetraaminocalix[4]arenes based on hydrogen bonding. Chem Commun. 2007;18(18):1813-1815.

5. Decher G, Lvov Y, Schmitt J. Proof of multilayer structural organization in self-assembled polycation-polyanion molecular films. Thin Solid Films. 1994;244(94):772-777.

6. Constantine CA, Mello SV, Dupont A, et al. Layer-by-layer selfassembled chitosan/poly(thiophene-3-acetic acid) and organophosphorus hydrolase multilayers. J Am Chem Soc. 2003;125(7):1805-1809.

7. Jaber JA, Chase PB, Schlenoff JB. Actomyosin-driven motility on patterned polyelectrolyte mono- and multilayers. Nano Lett. 2003;3(11): $1505-1509$.
8. Rusling JF, Wasalathanthri DP, Schenkman JB. Thin multicomponent films for functional enzyme devices and bioreactor particles. Soft Matter. 2014;10(41):8145-8156.

9. Shutava TG, Balkundi SS, Vangala P, et al. Layer-by-layer-coated gelatin nanoparticles as a vehicle for delivery of natural polyphenols. ACS Nano. 2009;3(7):1877-1885.

10. Tang Z, Wang Y, Podsiadlo P, Kotov NA. Biomedical applications of layer-by-layer assembly: from biomimetics to tissue engineering. $A d v$ Mater Deerfield. 2006;18(24):3203-3224.

11. Caridade SG, Monge C, Gilde F, Boudou T, Mano JF, Picart C. Freestanding polyelectrolyte membranes made of Chitosan and alginate. Biomacromolecules. 2013;14(5):1653-1660.

12. Chen J, Qiu X, Wang L, Zhong W, Kong J, Xing MMQ. Free-standing cell sheet assembled with ultrathin extracellular matrix as an innovative approach for biomimetic tissues. Adv Funct Mater. 2014;24(15):2216-2223.

13. Guan S, Zhang XL, Lin XM, Liu TQ, Ma XH, Cui ZF. Chitosan/ gelatin porous scaffolds containing hyaluronic acid and heparan sulfate for neural tissue engineering. J Biomater Sci Polym Ed. 2013; 24(8):999-1014.

14. Santoro M, Tatara AM, Mikos AG. Gelatin carriers for drug and cell delivery in tissue engineering. J Control Release. 2014;190:210-218.

15. Flory PJ, Garrett RR. Phase transitions in collagen and gelatin Systems1. J Am Chem Soc. 1958;80(18):4836-4845.

16. Macneil S. Biomaterials for tissue engineering of skin. Mater Today. 2008;11(5):26-35.

17. Ambrosio L. The role of biomaterials in burn treatment. Burn Trauma. 2014;2:150-152.

18. Dina R, Kristine VB, Albert H, Hans-Georg S. Insights into the mode of action of chitosan as an antibacterial compound. Appl Environ Microbiol. 2008;74(12):3764-3773.

19. Rowley JA, Madlambayan G, Mooney DJ. Alginate hydrogels as synthetic extracellular matrix materials. Biomaterials. 1999;20(1): $45-53$.

20. Rinaudo M. Main properties and current applications of some polysaccharides as biomaterials. Polym Int. 2008;57(3):397-430.

21. Heydarkhan-Hagvall S, Schenke-Layland K, Dhanasopon AP, et al. Three-dimensional electrospun ECM-based hybrid scaffolds for cardiovascular tissue engineering. Biomaterials. 2008;29(19):2907-2914.

22. Petrie TA, Raynor JE, Reyes CD, Burns KL, Collard DM, García AJ. The effect of integrin-specific bioactive coatings on tissue healing and implant osseointegration. Biomaterials. 2008;29(19):2849-2857.

23. Wu Y, Chen L, Scott PG, Tredget EE. Mesenchymal stem cells enhance wound healing through differentiation and angiogenesis. Stem Cells. 2007;25(10):2648-2659.

24. Wang X, Ge J, Tredget EE, Wu Y. The mouse excisional wound splinting model, including applications for stem cell transplantation. Nat Protoc. 2013;8(2):302-309.

25. Herndon DN, Spies M. Modern burn care. Seminars in Pediatric Surgery. 2001;10(1):28-31.

26. Ryssel H, Gazyakan E, Germann G, Ohlbauer M. The use of MatriDerm ${ }^{\circledR}$ in early excision and simultaneous autologous skin grafting in burns - a pilot study. Burns. 2008;34(1):93-97.

27. Boyce ST. Design principles for composition and performance of cultured skin substitutes. Burns. 2001;27(5):523-533.

28. Supp DM, Boyce ST. Engineered skin substitutes: practices and potentials. Clin Dermatol. 2005;23(4):403-412.

29. Kamolz LP, Lumenta DB, Kitzinger HB, Frey M. Tissue engineering for cutaneous wounds: an overview of current standards and possibilities. Eur Surg. 2008;40(1):19-26.

30. Wong DJ, Chang HY. Skin tissue engineering. StemBook. Cambridge, MA: Harvard Stem Cell Institute; 2009.

31. Zhong SP, Zhang YZ, Lim CT. Tissue scaffolds for skin wound healing and dermal reconstruction. Wiley Interdiscip Rev Nanomed Nanobiotechnol. 2010;2(5):510-525.

32. Rui X, Luo G, Xia H, et al. Novel bilayer wound dressing composed of silicone rubber with particular micropores enhanced wound reepithelialization and contraction. Biomaterials. 2015;40:1-11. 


\section{Supplementary material}

Video SI The free-standing nanomembrane was obtained after the gelatin base melted in the $37^{\circ} \mathrm{C}$ water.

International Journal of Nanomedicine

\section{Publish your work in this journal}

The International Journal of Nanomedicine is an international, peerreviewed journal focusing on the application of nanotechnology in diagnostics, therapeutics, and drug delivery systems throughout the biomedical field. This journal is indexed on PubMed Central, MedLine, CAS, SciSearch $®$, Current Contents $® /$ Clinical Medicine,
Journal Citation Reports/Science Edition, EMBase, Scopus and the Elsevier Bibliographic databases. The manuscript management system is completely online and includes a very quick and fair peer-review system, which is all easy to use. Visit http://www.dovepress.com/ testimonials.php to read real quotes from published authors.

Submit your manuscript here: http://www.dovepress.com/international-journal-of-nanomedicine-journal 